\title{
The North Laine: a visual essay.
}

\author{
YUILL, C.
}

2012

Copyright (C) Sociological Research Online 1996-2012. DOI: https://doi.org/10.5153/sro.2572.

Users who receive access to an article through a repository are reminded that the article is protected by copyright and reuse is restricted to non-commercial and no derivative uses. Users may also download and save a local copy of an article accessed in an institutional repository for the user's personal reference. For permission to reuse an article, please follow our Process for Requesting Permission. 


\title{
The North Laine: A Visual Essay
}

\section{by Chris Yuill \\ Robert Gordon University}

\begin{abstract}
The North Laine in Brighton provides a useful case study in exploring different ways of experiencing and imagining urban life. The area possess many distinctive street forms and supports counter-cultural lifestyles, which emphasise environmentalism and alternative forms of capitalism, such as cooperative and collective organisation of the workplace. Drawing on the ideas and theories of Henri Lefebvre the essay focuses on (1) the various social and historical process that have conditioned and influenced the development of the area and (2) the various social power relations that have both sustained the area, allowing it to develop into its current format, and in turn question its future. A visual methodological approach is used to present the data and to convey the distinctive aesthetic of The North Laine.
\end{abstract}

Keywords: Visual Sociology, Urban Village, Urban, Glocalization, Brighton

\section{Introduction}
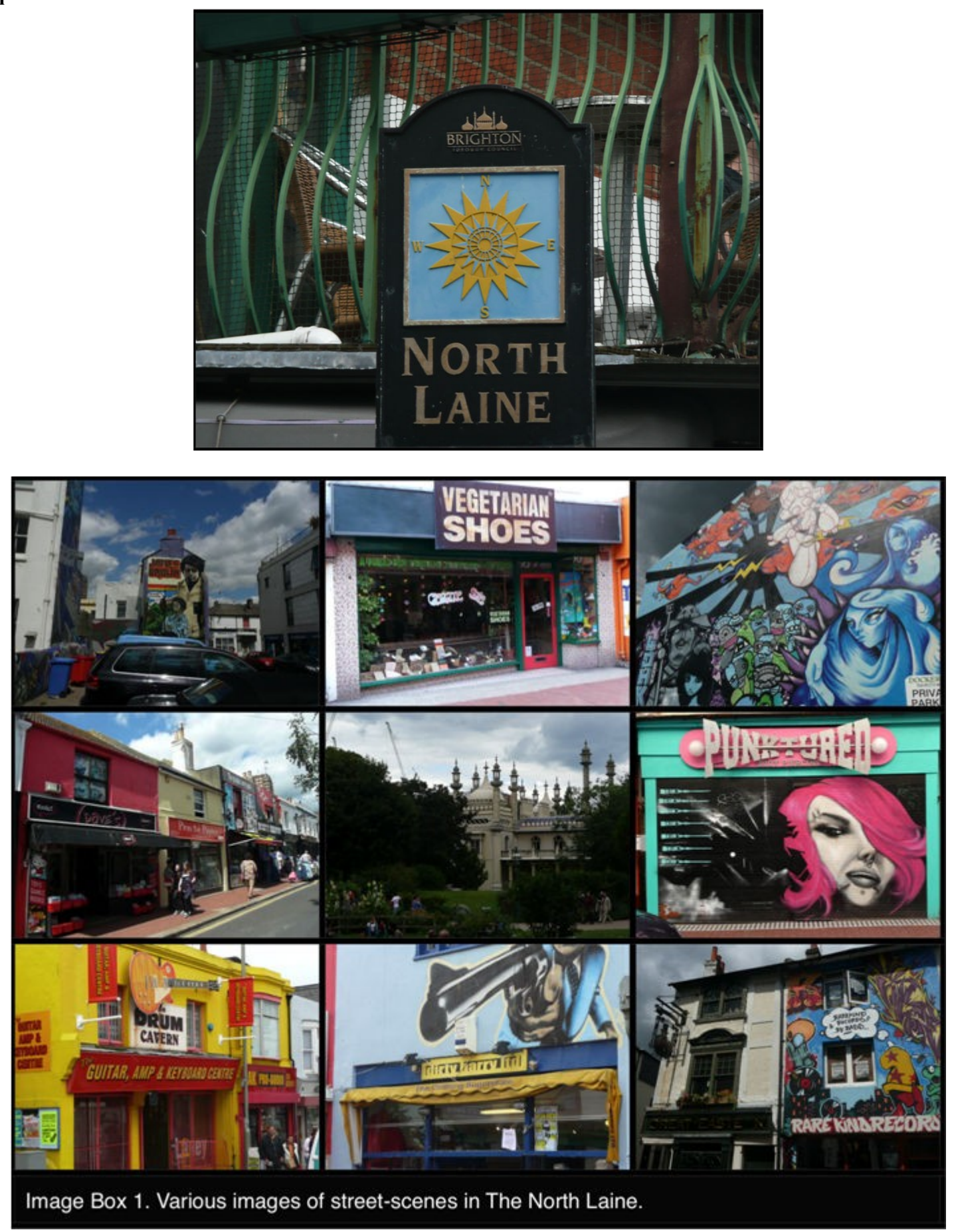
1.1 The North Laine is an urban village and cultural quarter situated in the English south-coast town of Brighton. As the images above and the video walkthroughs below indicate The North Laine, as an instance of urban space, displays a highly distinctive and colourful aesthetic style. Many of the shops and retail outlets in The North Laine also offer some form of alternatives to mainstream capitalism and high-street retail, by selling products that are concerned with environmentalism, vegetarianism or fair-trade; or where the business has been founded as a worker's cooperative. A further note of distinction is provided by the many colourful large-scale instances of street art and murals that are situated throughout the area. The combination of the idiosyncratic shop fronts, the alternative consumerism and the street art make this an area that is both countercultural and cool.

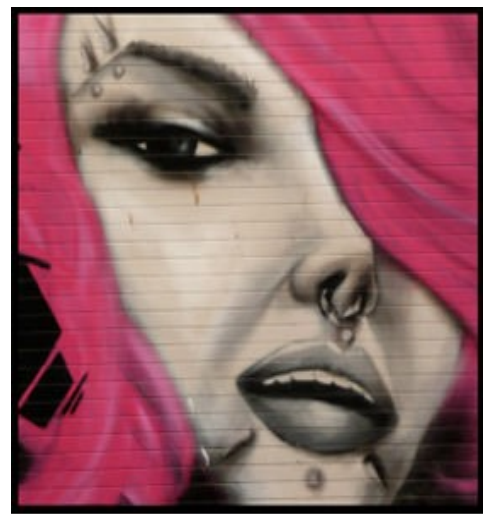

Walk through Videos:

Sydney Street

Kensington Gardens

Gardner Street

Gloucester Road

1.2 What I wish to specifically tackle in this paper are two interrelated issues. The first is how The North Laines as an urban space comes into being, identifying the necessary conditions for the development of its unique spatial aura. The second is concerned with how the The North Laines as an example of a vernacular idiosyncratic local space can maintain its identity in relation to the wider and deeper global social and spatial processes. Tackling these themes will provide further insights into how such quarters can come into being in the first place and how the wider and deeper process and forces of globalization play out in a distinct locality. The main point I shall be arguing at this stage in the paper is for a subtle and nuanced approach to globalization as it pertains to urban space that understands the process to be more than a monolithic one-way street, but rather one of fusion and blending that can potentially add to the local as opposed to detracting from it. The reason for my decision to focus on one area or community is guided by Crow (2002). He argues that studies of particular places or communities assist in providing valuable empirical insights into wider theoretical debates where novel ideas are generated but are unfortunately supported by a paucity of evidence.

1.3 To meet the ambitions stated above this paper unfolds in the following sections. The first section briefly summarises the wider literature that has explored urban space and issues surrounding urban villages and cultural quarters. After contextualising this paper in the literature, attention turns in the second section to the method that was used to gather data, with an emphasis on discussing the role of the visual in sociology. The third section deals with the history of The North Laine. The focus here falls on both internal and external influences, such as the transition from feudalism to modernity, deindustrialisation and the role of chance. Once the history of the space is laid out, attention then turns to how The North Laine engages with the process of globalization. Finally, a conclusion brings together all the main points.

\section{The Urban Village and Cultural Quarter}

2.1 There has been a proliferation of writing recently exploring various social, economic and cultural dimensions of what are termed urban villages or cultural quarters. Urban villages are identifiable by offering an urban space that is supposedly rich in historical authenticity, aesthetic difference and provide distinct forms of cultural and economic consumption that cater for particular varieties of cultural capital. It was one of Zukin's (1989) earlier works on the reordering of New York's SoHo that begins this current interest in urban villages and cultural quarters. In that research Zukin traces how artists were attracted by cheap rents to a former garment manufacturing area in New York that had fallen into disuse. Recent work on urban villages has explored a variety of areas including British examples, such as Nottingham Lace Market (Tiesdall 1995; Shorthose 2004), Birmingham's Eastside (Porter \& Berder 2007) Manchester's Northern

2.2 Quarter (Brown et al 2000) or global examples, such as Milan's Ticinese quarter (Bovone 2004). A recent edited collection by Bell and Jayne (2004) also outlines a number of examples of urban villages in Britain, Australia and the USA. One should however also not forget the rich vein of older material in addition to these more contemporary examples, including such studies as Young and Willmot's (1962) classic work on Bethnal Green or Gans' (1962) analysis of Italian-Americans living in Boston's West End.

2.3 Urban villages, as Zukin (1998) points out, have come into being as the city has moved from being a place of production to a place of consumption and identity and are aligned with the post-industrial (if not post-modern city) where an over-arching single identity has given way to a multiple forms of identity within the city. That observation is useful in identifying the macroprocesses at play behind the creation of urban villages but the actual creation of an urban village on the micro-level or street-level relies on activity in a particular place that possesses certain economic and cultural resources alongside a particular built environment rich in distinctive buildings and interesting spatial arrangements of buildings, pathways and public spaces (Montgomery 1998, 2003). Shorthose (2004) usefully points to how cultural quarters can be classified as being what he terms 'engineered' or 'vernacular'. As is implied in the name, engineered urban villages are the product and outcome of planning and policy decisions, specifically planned to cater for the new cultural and creative industries. To that extent they can be described as being synthetic attempts to construct order and identity in urban space. Many recent examples of cultural quarters or urban villages in British cities can be deemed to be engineered and come into existence as part of urban regeneration projects. 
2.4 The vernacular urban village is the opposite of the engineered, its existence emerging out of the efforts and ambitions of social agents in a particular place and accrues over time gradually transforming that place into a recognizable urban village or cultural quarter. Examples of the vernacular could include the Left Bank in Paris or Soho in London (Montgomery 1998), areas that have evolved over time into a distinctive cultural space. Shorthose (2004: p171) also argues that the vernacular examples of urban villages or cultural quarters posses certain advantages over the engineered by not being aligned to the needs of profit and focused more on self-realization and fulfilling forms of creative labour:

" Given these intrinsic qualities vernacular cultural participation is more intimately connected to an increase in cultural vibrancy, a sense of cultural ownership and authorship, and to better quality of urban life. It offers the possibility of a form of cultural economic production that is much more intimately connected to 'wellbeing' (Hamilton 2003), and which hints at the real possibility of de-alienated work and autonomous creative expression (Fromm 1966; Gorz 1999)."

2.5 Before concluding this overview of the literature there is one caveat to record. First, some of the material cited above comes from academic areas external to sociology. The inclusion of which may be appear to be problematic given that this is intended to be a sociological treatment of the urban space of The North Laines. As May and Perry (May et al. 2005) have noted, however, the study of the urban has for some time been an interdisciplinary endeavour. What sociology brings to the table is a wider range of theoretical tools, such as globalization, and, as Savage et al. (2003) advance, an understanding of how and why the urban relates to wider issues of modernity. Such tools combined with an emphasis on the social are included throughout this work.

\section{Method}

3.1 A visual ethnographic method was adopted in order to return and gather data for this research. The form of ethnography adopted here mainly involved walking through the various streets or observing social encounters in a style that Wogan (2004) describes as 'deep hanging out'. The collection of data took place between 2007 and 2011, though mainly in the summer months of 2007 and 2008. A further round of data collection took place in the summer of 2011 to ensure that there had been no major changes to the area in the intervening three years and to gather more video footage. Data was recorded in two ways. First, the conventional notebook, in which I recorded experiences, observations and reactions to what I was encountering. Sometimes these notes were just rapid fragments hastily jotted down hoping to capture a particular observation, other entries were more considered and followed a period of reflection. The second approach involved visual sociology employing a digital camera that had the facility to record both still and video images.

3.2 Using visual techniques offers sociology the possibility of developing a much richer and wider mode of representing, analysing and discussing society, by going beyond what Henny (1986) playfully terms the 'Gutenberg syndrome' in sociology that prioritises the standard form of communication as word-text and is dismissive of other media that can communicate with equal power an analysis of society. In the context of this essay so much of what I interrogate is mediated through visual experience and visual spectacle, and, consequently, raises a distinct challenge. Trying to adequately communicate the visual displays and visual textures in conventional text format would be beyond my literary skills. As the various images embedded into the text illustrate a textual description the ornate and highly artistic streetscapes would be difficult to fully realise and hence an integral element of what the makes the object interesting to study would be lost. As Chaplin (1994: p 221) rightly insists that with the visual we are required ' - to appreciate them for what they document as well as for their visual appearance'. Using a textual descriptive approach would also be difficult to meet the standard stylistic confines of the journal format with the (highly) justifiable restrictions on word-count, thus limiting the scope of analysis and discussion. These points should, however, not be read as claiming any superiority for the visual. The visual may powerfully document elements of social life, such as Salgado's evocative pictures of Brazilian miners labouring in the Serra Pelada (see Strangleman 2004), but the visual cannot provide an analysis or theoretical interpretation by its own presence. An image may speak a thousand words but a thousand or so words are necessary to provide the sociological context and sociological analysis of an image or images. Text, therefore, remains important. Following Chaplin (op cit) once more, it the synthesis of text and visual image that adds bite to the representational and analytical ambitions of the sociological imagination.

3.3 There are qualities about space that the visual ethnographer captures taking a photograph that differ from a tourist doing something similar. As Shields (2004), following Crary (1999), notes ' - the gazing observer occupies a location at the intersection between the body and a network of practices, institutional methods and technologies'. So, instead, of the images being taken to record a moment on holiday, for example, they are included to capture an aspect of The North Laine that is in some way sociologically instructive or meaningful. The images, in context of this paper, serve to relate the data that was gathered during the study in addition to providing an illustration of the main features of The North Laine.

3.4 Videoalso features withinthis essay, which, as amedium, offers anadditionaladvantagetothemany advantages provided by still images when documenting the city: movement. As many classic urban commentators agree the city is about what we do in it, how we traverse the streets and walk along the pavements filtering and absorbing the constant mass of sensations and experiences presented to us by city life. So, forexample, Jacobs (1961)points tothe centrality of busy interactive streetwalk cultureas giving rise to the energy and creativity of urban space. For Simmel (1971) it is each step through the urban environment thatpropels encounters withnewideasandpeople; fordeCerteau(1988)itisonlybywalking through the city that one fully appreciates its reality; and for Park (1950: p viii) ' - tramping about in cities _ ' was the best method by which to interrogate urban experience. Movement also features prominentlyinLefebvre, especiallyevidentinwhatheterms spatialarchetonics, where themovements of embodied human agents produce, experience and contest the urban. That attempt to capture the embodied moving experience of the city is the reason for the inclusion of the video in this essay. The various clips thatcanbeaccessedare of key moments and experiences of The NorthLaine that provide insights into the unique characterof The North Laine as an urban space. By viewing the video some of that experience of being in The North Laine becomes accessible. 
3.5 Finally, given the historical element within this paper some limited historical research was undertaken at Brighton Library and at Brighton Museum, with the objective being to identify key moments in the history of the North Laines area. Primary source historical books and documents were identified in consultation with staff in both locations. Research using maps and census data housed in Brighton Museum was also undertaken. Such research requires a whole methodology in itself and therefore only supplementary and illustrative data was sought.

\section{History - what is there now comes from what was}

4.1 Therearetworeasons prompting thehistorical element of this essay. The first promptis provided by Montgomery (1998) who identifies that history and sense of place are essential aspects of a cultural quarter. In many of the examples of urban villages or cultural quarters discussed earlier a strong local history exists that(1)explains why that particularplacedevelops into acultural quarterand(2)signals the character and identity of place as being different and unique from other places within the same urban context. The second prompt is providedby urban sociologist Lefebvre(1991), who emphasises that the historyofa placeisimportantinunderstandingtheproduction of thatspace. Very few spacesemergefrom nothing without any provenance, all have lineages and a history that are crucial to the subsequent development of that space, andwhich in turn exert some form of presence in the present. Oras Lefebvre (1991:p228) stated, 'The preconditions of social space have their own particularway of enduring and remaining actual within that space $\ldots$ '. The main lesson that emerges from this historical review of The North Laines is that it fits with Shorthose's description of a vernacular cultural quarter, one that has organically emerged froma range of interrelated factors and events that are discussed below in greater detail.

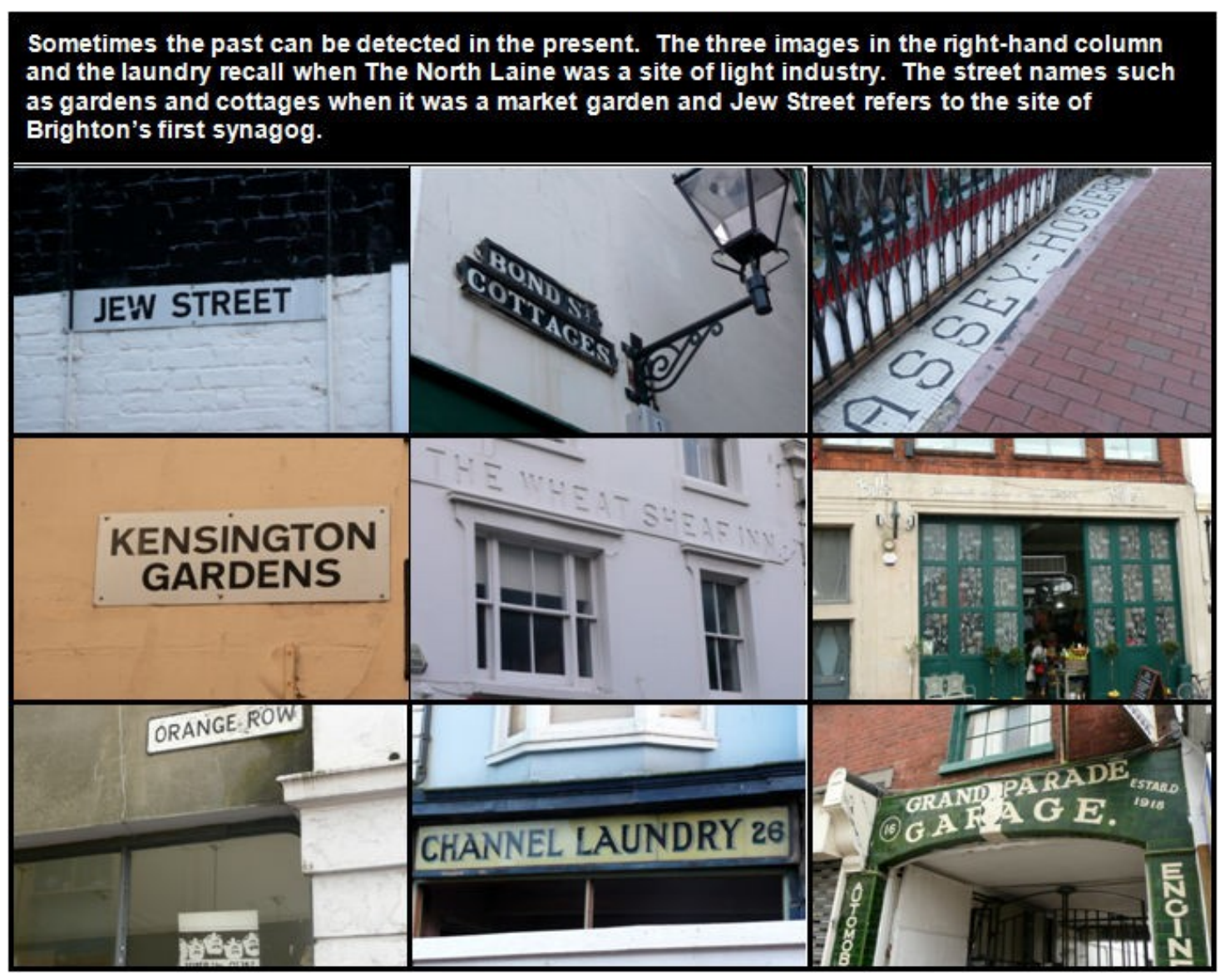

4.2 Brighton as a whole is an example of what Shields (1991) formulates as being 'a place in the margins', part of the alternative geography of modernity, a site of the carnivalesque, a marker of difference, and a place of permissive licence for otherwise forbidden desires. He also provides a useful historical insight into the various processes and reasons why the small and insignificant fishing village of Brighthelmstone became the vibrant and chic town of Brighton (Shields 1991: Ch 2). The story of this transformation begins with the flamboyant playboy figure of George IV, who founded the myth of Brighton as a place of pleasure when he was Prince Regent, in the late 1700s. Monumentally the Indo-Saracen inspired Royal Pavillion still stands as a reminder of that time. Monuments, such as The Brighton Pavillion, also play a particular spatial role for Lefebvre (1991), as they inform the texture of a space, providing a set of codes and signs as to what that space is about, how it is perceived, conceived and lived. It also records an interpretation of another dimension of space that occurred with the reordering of global space brought about by the expansion of the British Empire. India and the East in Regency England were regarded by certain elements of the bourgeoisie as an exotic and romantic other that was worthy of emulation and respect, a discourse of the Orient that stood in stark contrast with the later Victorian supremacist discourses of Indian backwardness. From an early stage in the creation of The North Laine, the view of the powerful and hegemonic forces (in this case the upper echelons of British court society), was one that created a ludic space where some of the otherwise normal constraints concerning spatial practices and the use space in English society were suspended. 


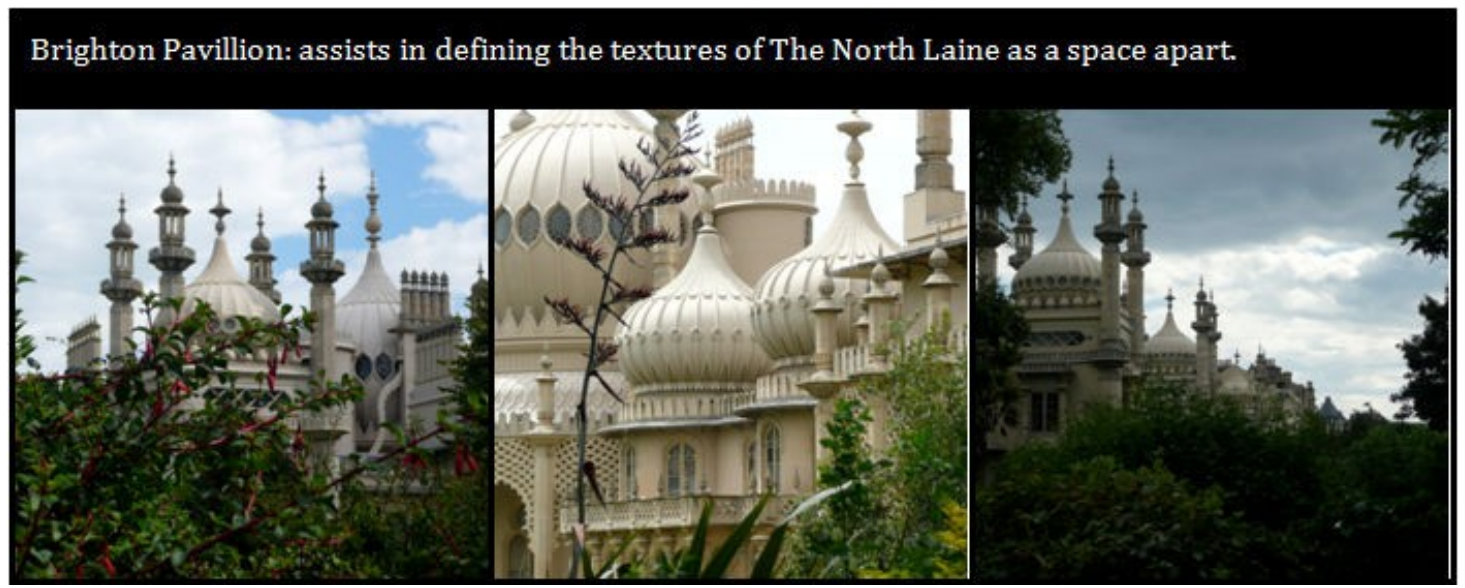

4.3 The popular perception of Brighton, Shields continues, as a place of permission and difference is further advanced by the later creation of the beach as liminal place of recreation allowing for the transgression of Victorian bodily norms with the new fad of sea-bathing necessitating displays of bathers' partially dressed bodies further strengthened Brighton's reputation as somewhere that was different from the staid order of other towns and rival leisure destinations such as Bath. The idea of permission granted by being set from form the restraints of normal everyday-life to break accepted pattern of behaviors is also evident in the (dark) carnival violence of the Mods and Rockers clashes of the 1960s - the historical event captured in Cohen's (1972) classic moral panic work.

4.4 This discourse of permission still pertains today as indicated in the following field note from an observation on The North Laine by a young woman (c.19 years old) working in a coffee shop:

"It's so laid back here. Nobody cares what you get up to." (Field Note June 16th 13.11)

4.5 The main thread that unites all these events in the historical narrative is that Brighton became a site and place where normal social mores and social norms could be - albeit, within certain limits - suspended, and license and permission existed for people to test the boundaries of their own lives free. Brighton emerges then as a place of difference, spectacle andrelease:

"In an overarching social spatialisation of Britain, the place-myth of Brighton is located in an imaginary geography vis-a-vis the place-myths of other towns and regions which form the contrast which established its reputation as a liminal destination, a social as well as geographical margin, a 'place apart'." (Shields 1991:p112)

4.6 While the above material provided by Shields diligent historical work on Brighton as a place-myth makes clear the origins and developments of the symbolic imaginings and perceptions of Brighton, a further material history needs to be added next in order to establish how the distinctive built-environment of brick, flint, concrete, paint and glass came into being and how the symbolic aspects of license and permission translate into spatial and social practices centered in a specific and distinctive physical space. If we do not consider the actual material basis and construction of a space then we run the risk of lapsing into idealism once more. After all, the question of what is it specifically about this part of Brighton is different as opposed to other districts in the city remains unanswered. In particular how the distinctive tight-street pattern came into being. Such a spatial arrangement in an urban setting is a necessary element throughout Jacobs' (1961) work in creating interesting, creative and vibrant places in which to live. To understand why and how the current built environment came into being, again requires a stepping back in time but one where the focus is on the rise of the built and experiential environment.

4.7 Space is not just an entity, or a void, waiting to be filled, as there is no space outside social relations. It emerges out of various relations and is dynamically reordered, imagined, experienced and materialised in connection with changes in dominant cultural and economic processes occurring in historical time. All space for Lefebvre (1991) is both metaphorically and literally 'up-for-grabs' by capitalism and the shift from feudalism to modernity and the rise of capitalism witnessed a complete reordering of rural and urban space (see also Harvey 1989). Woods (2002) discusses the centrality the transforming of land for capitalist purposes within the wider historic rise of capitalism in Britain. At its peak this process is most vividly witnessed in the enclosing of the commons (though other forces were at play) where the peasantry lost both access to physical land and space but also to the idea and concept of land being open to all and not the private property of a few. In Brighton, however, the large-scale transference of land did not occur as it had in other parts of England. The common land was instead sold off in strips and parcels dictated by ownership and access to the land by individual small-property owners. The open-fields surrounding Brighton followed a common pattern across feudal England of communal ownership consisting of long strips and walkways as indicated in image below. It is this pattern of field ownership that gives rise to the quarter's name of The North Laine. The spelling of Laine is not a 'olde englishe' variant of lane, but rather is derived from the ancient Anglo-Saxon meaning 'loan' or lease', referring to the open commons that existed throughout Britain during feudalism and to the way in which land was sub-divided into different plots tended by tenant husbandmen (Carder, 1990) In Brighton the fields were divided into furlongs, separated by 'leakways', which acted as pathways between the fields, and then further sub-divided into 'paul-pieces', an eighth of an acre in size. Similar (though with local variation) land holding patterns were eventually ended by the enclosures of the eighteenth century. Private capital and private ownership at this point reordered the symbolic, legal and spatial order of the former common land in the early phases of agricultural capitalism to that of private property. This capture and command - albeit problematic and fraught with contradictions - of space is, as Harvey (1989: 232) notes, fundamental for capitalism and its requirement to 'rationalize spatial organisation into efficient configurations of production'. The common lands were however and unusually not, as mentioned above, enclosed for agricultural purposes in Brighton as happened elsewhere in England. Brighton's main economy in the mid to late 1700s faced out to the sea with farming of secondary importance to fishing. The plots of land were instead sold for housing and light industry. The sale of land was thus in turn determined by the existing feudal field system with plots of land sold in their 
subdivisions, as and when, they became available. This piecemeal selling off the land laid down the current street pattern that is present today. The relationship is usefully illustrated in the figure below. A parish map of 1792 records the field system around the square shape of the Brighton, bounded by West, North and East Streets. The present street system is becoming visible in the map from c. 1820, where the old field-strips are becoming thenew streets and lanes.

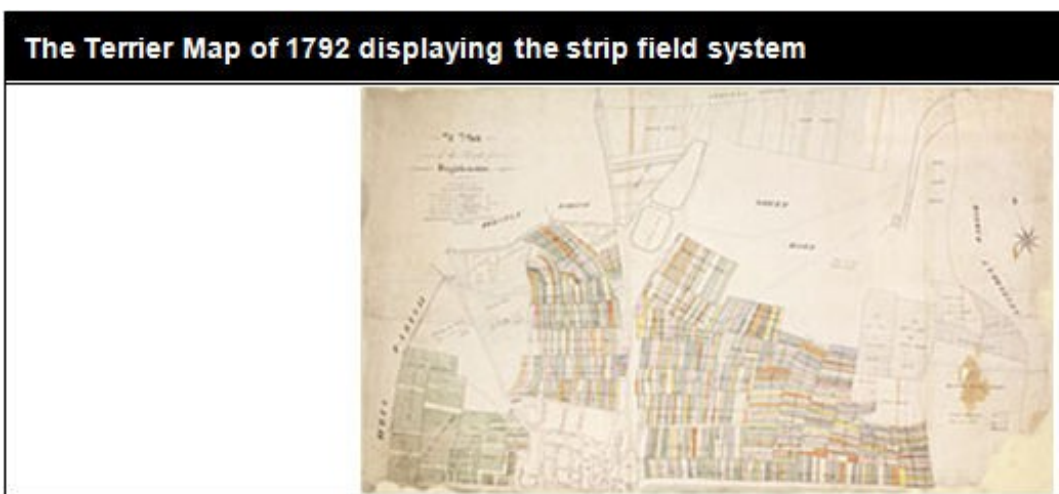

In this map from c. 1820 the field system depicted above is being transformed into the current street layout, but the actual topography is preserved.

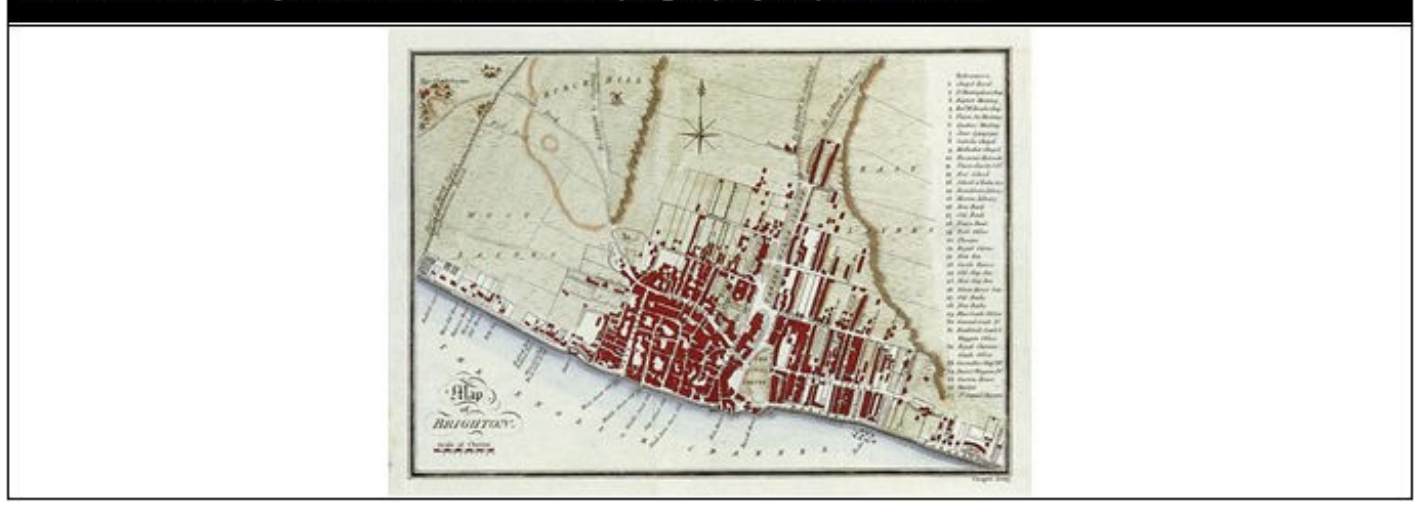

4.8 In common with other areas within larger urban structures that can be described as cultural quarters, a certain level of 'accident' or unintended consequences pertains in relation to the North Laines coming into being. The unique built environment surviving in part by the dint of chance and historical circumstance. Montgomery $(1995,2005)$, for example, has noted accident playing a role in the development of the Templebar area of Dublin, where an abandoned attempt to redevelop the area as a bus terminal, resulted in the unintended preservation of series of idiosyncratic old streets that because of both their low rent and aesthetic difference attracted artists, galleries and musicians to live and work there. While traditional parts of Bristol in the citycentre were lost in the 1960s when, as with many other places in the United Kingdom, local authorities embarked upon what was then regarded as being a programme of 'modernisation', introducing Brutalist concrete architecture and new road systems that were constructed out of the spaces left by the demolition of older street layouts. If the recommendations of the $1967 \mathrm{Wilson}$ and Womersley Report had been put into practice, for example, much of the current North Laine would have been flattened to make way for a flyover. Brighton also escaped the heavy bombing during the Blitz in the Second World War that destroyed the citycentre of Southampton, where the Victorian town as a built entity is all but gone and survives mainly in the street plan and in the street names. The vast majority of structures in Southampton that exist today were built form the 1960s onwards, arguably lacking the vernacular distinction afforded by the more traditional designs, which are still evident in Brighton North Laine. 


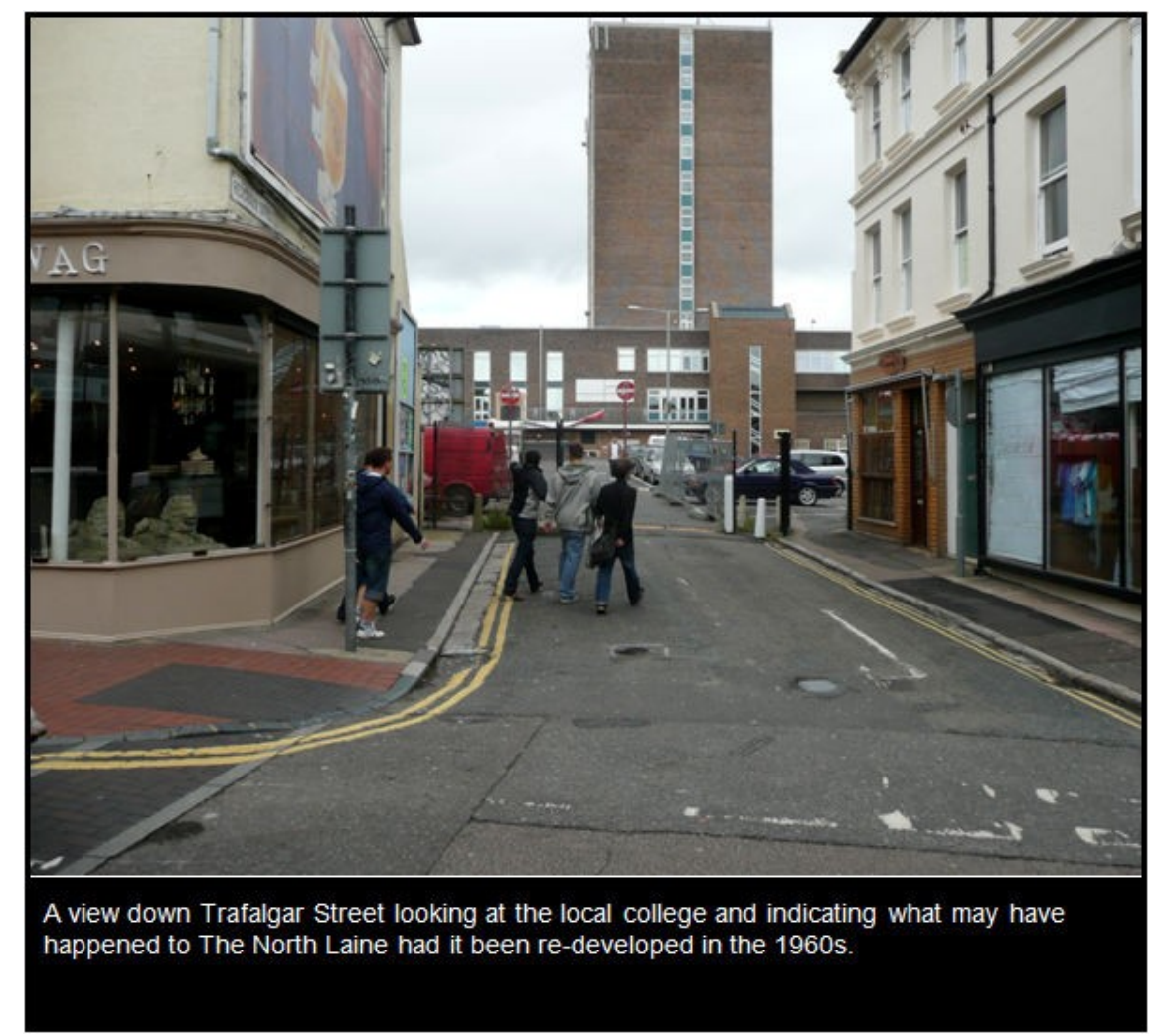

4.9 During the 1960s and 1970s the area underwent its own period of deindustrialization as is common to many cultural quarters. In the classic cultural quarter narrative it is artists, writers and musicians that move into a former industrial area, attracted by the low rents, authenticity and so forth. Here The North Laine differs in that the people who moved into the area were engaged with alternative politics (socialism, anarchism, and environmentalism). The political character of the people that moved into The North Laine was evident in the shops that emerged in this period, examples including The Unicorn Bookshop, Infinity Foods, Solstice Bookshop and the first ever Body Shop. The following extract from a recollection by Paul Bennett who worked in an alternative bookshop captures the move away from the light industry to the new countercultural industries and the reason why they were attracted to the area:

'The North Laine was deeply unfashionable in the 1970s so rents were more reasonable. Our landlord was Murray Gordon, owner of Sammy Gordon's, a trendy, mainly Italian, suit shop in North Street. One of his staff lived upstairs and I think No 28 may have been Murray Gordon's tailors before we took it over.' (Paul Bennett 2011: n.p.)

\section{The Global and the Local}

4.10 The previous section has explored the genesis of The North Laine identifying the various social processes and plays of chance that have provided the conditions for the current countercultural and cool urban space to come into being. Urban space is never still, however, and is never at the end of its own history. The North Laine, as with anywhere else, should be understood to be in a constant state of flux and transformation. The main engine of change affecting the North Laine today, as with any urban space, is globalization and that is the focus of this section.

4.11 Globalization here is not held to be a one-way street that automatically homogenizes urban space. Globalization can on the contrary hold the potential to offer cultural resources that enhance and further heighten the individuality and distinction of an area. As Sassen $(2000,2001)$ has notably discussed, urban locations and cities are inextricably bound in with globalization, as places from where processes of globalization originate, whether economically or culturally, or as places that are shaped by globalization. Globalization, then, is something that urban spaces do as well has having done to them. In a recent study on globalization and identity in Manchester, Savage et al (2005), also identified that globalization in an urban context is highly complex and far from being monolithic in its power and effect. They contend that current society is far from making an epochal shift towards a full-scale globalization that negates the local. Instead, what is occurring is that the local and the global are mixing and interrelating in subtle ways that assist in shaping the local context of people's lives. The ability of globalization to perform such a role in The North Laine is already present in the form of Brighton Pavillion and is alluded to in the previous section. A more modern instance of this tendency is evident in the street art (see the images below) that proliferates in The North Laine and that is where the discussion focuses on next. 

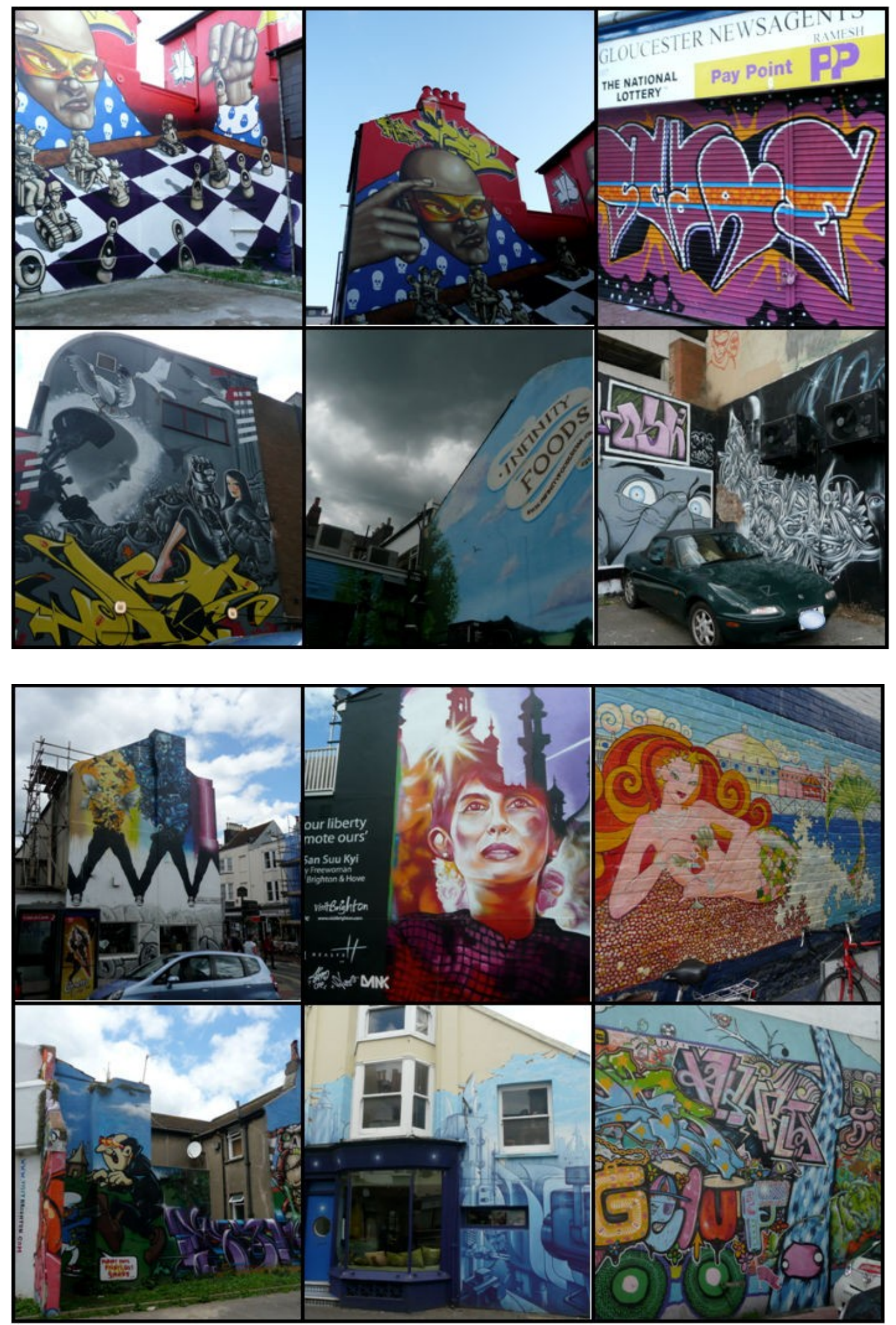

4.12 In the four intervening years of the two main phases of data collection (2007-2011) the number of murals increased significantly, though murals have been present in the area since the late 1960s with The Unicorn Bookshop being possibly the first example of this practice (Fuller 2011). In 2007 the murals were mainly to be found in Kensington Street, but in the last few years murals can be found in a number of locations within The North Laine. As the image box below highlights the aesthetic style of the various murals differ widely referencing and sourcing American-style graffiti, Japanese Manga, English pastoralist styles, English graffiti artist Banksy or individualistic artistic works. Images are drawn from both global and local sources. Now deceased Black American soul-singer James Brown and Burmese dissident politician Aung San Suu Kyi being obvious examples of global images, while the most obvious examples of local images are provided by reference to Mod culture (see below), which as a subcultural youth group is bound up with the history of Brighton, as the town was one of the locations of the (in)famous Mods and Rockers clashes of the 1960s, as detailed by Cohen. It is often the Vespa scooter, the Mod's favoured mode of transport, that is invoked to act as shorthand for the subculture as a whole. 


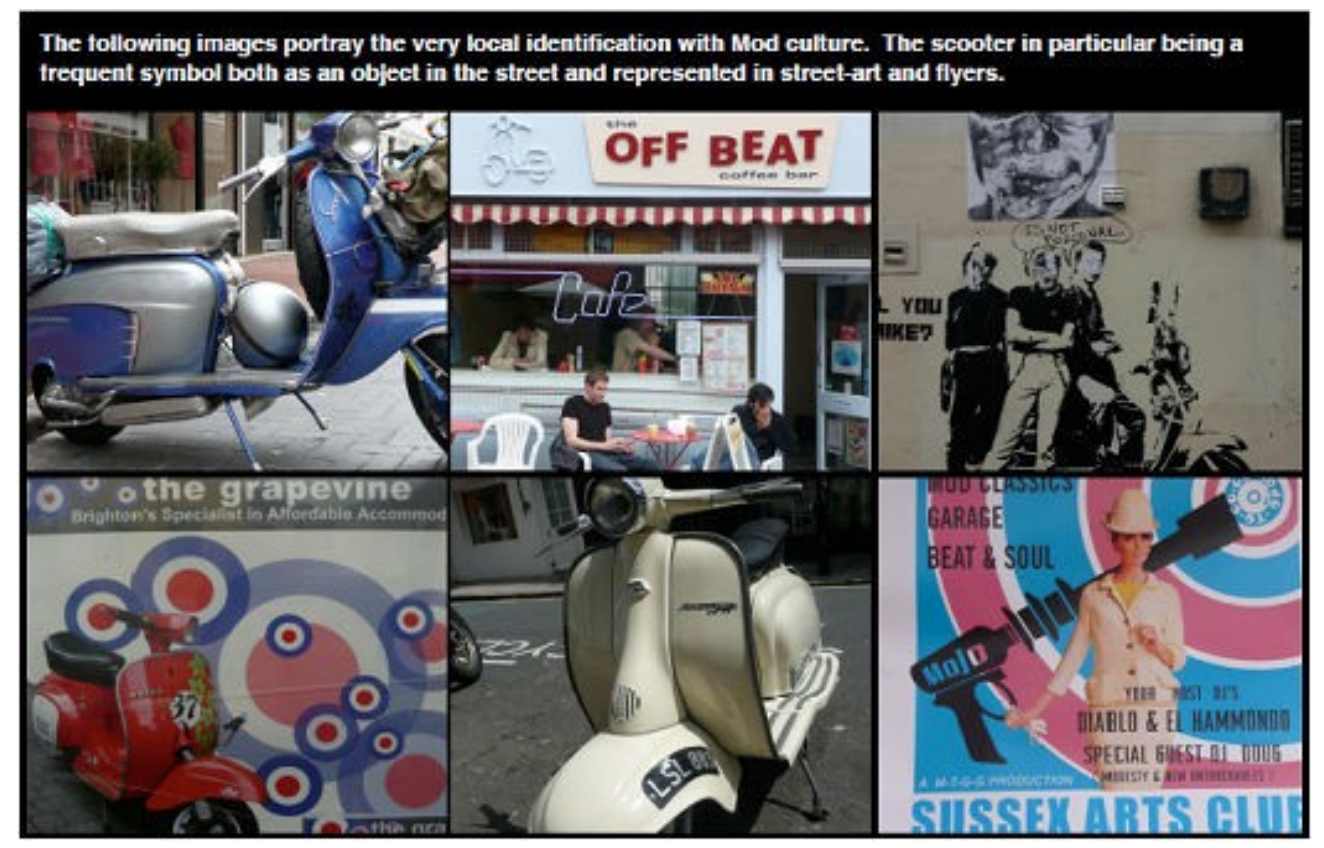

4.13 Overall, the presence of the forms of global culture discussed above adds to the distinctiveness of The North Laine and do not present any countervailing tendencies. What is important here is that the various examples of street art should not be considered in isolation from both the context in which they are to be found. The instances of street art should rather be understood in how they dialectically interact with other elements of The North Laine, such as the shop frontages, the street pattern and the flint-rubble material that the buildings on which the murals are painted and the historical flow that has allowed The North Laine to come into being. The lived experience, the effect of walking through The North Laine (as illustrated in the video below), is one that is mediated by the fusion and interplay of particular moments of the local and the global resolving themselves in the unique moment that is The North Laine. The work of Benjamin and his concept of aura is of use in expanding on this point further. Even though, he intended the term to apply to art and unique experiences of a particular moment in time, the concept of aura can, as Merrifield (2002) has argued, be applied to urban contexts too. What one finds here is that an urban space emits aura as its totality creates a unique urban spatiality and a set of experiences that are not available elsewhere and it is this particular fusion of global and local images and traditions that are embedded in the tight street system and countercultural shops that generates the aura of The North Laine.

4.14 The street art also provides a useful example of Robertson's (1995) concept of glocalization, which offers a corrective note to counter excessive pronouncements of the tendency for global and local to be abruptly counterpointed against one another without exploring how the two interpenetrate each other creating a specific place that emerges out of local particulars and global universals. Massey (1994) has made a similar point concerning how the most apparently banal of streets that seem on the surface appear locked in a prism of the particular and local, are actually on deeper inspection suffused with global influences.

4.15 The street art may present a moment of 'positive' globalization, where a new local particular emerges from the interweaving of global and local images and traditions. There are also 'negative' examples of globalization occurring with The North Laine and can be noted by the recent arrival chain stores to the area. Their presence chimes with what McGuigan (2011: p7) terms as being 'cool capitalism', a phase in contemporary capitalism that attempts to draw in and valorise counter-cultural symbols and objects, which, in their genesis, were intended to posit an oppositional form (whether weakly or strongly) to capitalism. McGuigan (2011) sees this development as the 'incorporation of disaffection into capitalism itself'. One mechanism (and there are multiple others) of achieving this appropriation of cool, is by physically situating a corporate chain store near or in an areas deemed to be cool, with the intention of gaining cool by association - a process that can be seen to be occurring in streets. Such a process is evident in a development on Jubilee Street (see video and image below) where the buildings are in a modernist universal style where both building materials and design bear no relation to the local vernacular. The development also provides retail units for corporate brands (Starbucks, Pizza Express, Giraffe, and Nandos, for example) that break with the independent culture of The North Laine, in effect forming a 'corporate quarter' in the cultural quarter. 


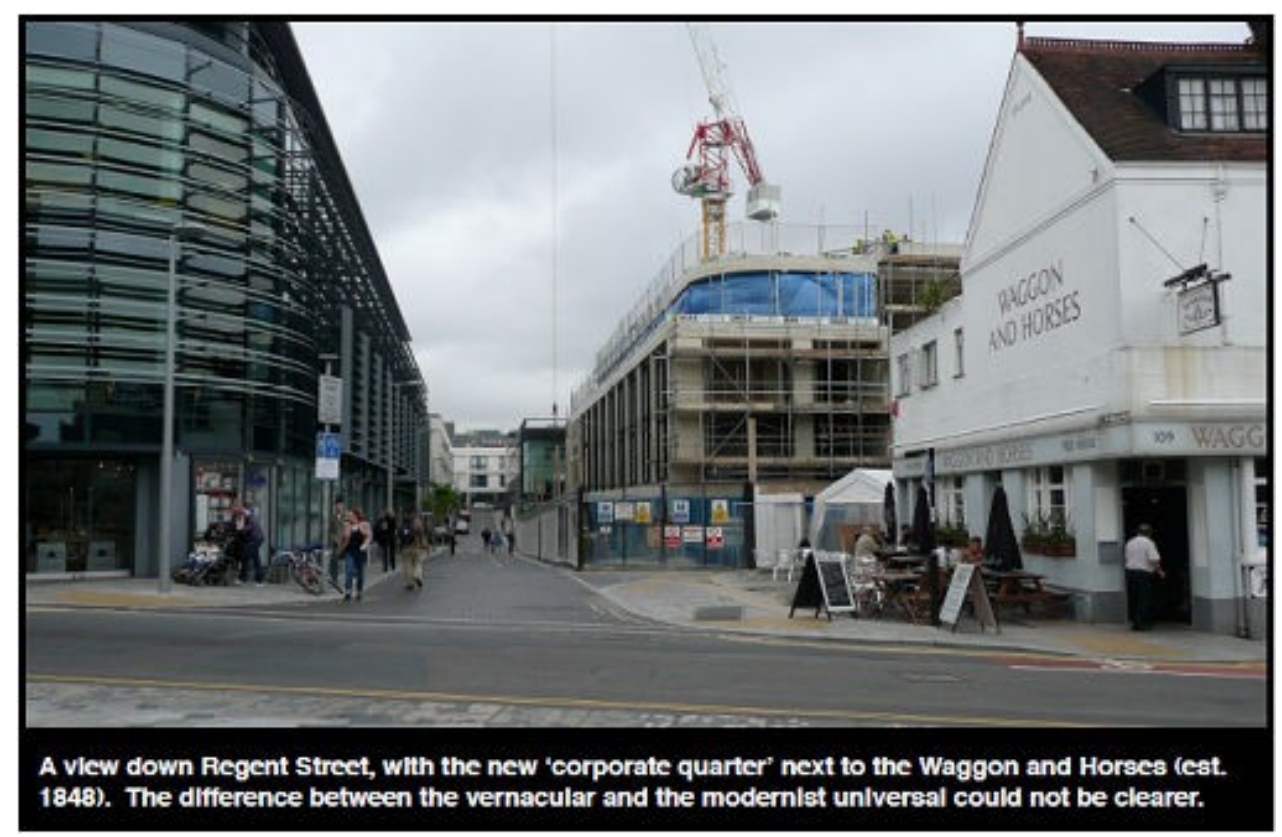

4.16 Care must be taken however not to jump to conclusions about the long-term effects of this development. Thompson (2004) highlights that two different perspectives on brands and the impact they exert on local culture exist within the literature. First, there is the cultural homogeneity perspective that has been advanced by Klein (2000). This perspective holds that brands exert a strong and devastating impact on local vitality resulting in the replacement of local and distinctive cultural vitality with bland corporate. Lineages of the homogeneity approach can be detected in Benjamin's (1999:p215) concept of mechanical reproduction and aura, mentioned earlier, where one of the impulses of capitalist modernity is to mass-produce cultural experiences, where, "By making many reproductions it subsitutes a plurality of copies for a unique existence". Benjamin talks specifically of art, but the notion of sameness and reproduction can be rolled out to also include urban experiences generally Starbucks usefully provides an example of this mechanical reproduction. As Ritzer (2008) has noted in his Starbuckisization thesis, both the actual aesthetic and build of Starbucks coffee shops are uniformly similar the world over as are the experiences one encounters, with their theatrical but manufactured aura of 'cool' and faux-bohemianism.

4.17 The homogeneity approach contrasts with the heterogeneity approach as advanced by Miller et al. (1998). This anthropological interpretation of shopping and urban commercial space indicates something more complex occurring in terms of how globalization is interpreted and received. The presence of international brands within a locality is here not a zero-sum game where all is collapse into the same bland corporate horizon but instead the presence of produces a highly varied local field for local social actors to both interpret and, importantly, to perform their identities. What the brand stores add is both a symbolic and material presence that can inform and reinforce oppositional ideologies to multi-nationals. So, instead of local people being instantly beguiled into the corporate experience they may find their anti-corporate convictions strengthened. The end result being the local coffee shops, for example, thriving as more people make a statement by choosing to take their custom to such places and avoid the corporate 'homogenizers' such as Starbucks.

4.18 In the North Laine, it is hard currently to make a call as to which perspective is analytically more robust in understanding the impact of the 'corporate quarter' within the cultural quarter: the reason being that the moment of the contradiction is still being played out. On one hand, the streets around exhibit very strong instances of a cultural homogenization. The local built vernacular is absent, giving way to a modernist design that could belong in any contemporary global city or town. There are no local stores but instead a variety of brand chain-stores that are common to most British high streets. This process of flux must be underlined as change is always immanent, and what is there is one moment is not necessarily there the next. Lefebvre (1991: p 49-53) brings attention to how capital creates what he terms 'abstract space' (a spatial adaptation from the Marxian theory of abstract labour), where over time all space can be disembeded from its specific history, losing its distinctiveness and falling prey to the super-signification of capitalism with its own set of symbols and signs. Abstract space, however, is a process and one that while immensely powerful is not guaranteed always to succeed in its own terms. Lefebvre also points to 'differential space' coming into being, a space that, while lacking the various economic, ideological and symbolic power, of abstract space, nevertheless can arise to confront and subvert the colonizing impulses of capital. Key to achieving this aim of differential space are the ' - energies of groups capable of subverting homogeneous space for their own purposes', whose actions create a ' - theatricalized or dramatized space' (Lefebvre 1991: p 391). So both abstract space, in the form of universal building styles, and differential space, in the form of the theatrical murals and shop fronts, are simultaneously present. Which one will 'win out' is yet to be decided, but currently they provide a tension that produces the space of The North Laine.

\section{Conclusion}

5.1 The focus in this paper has fallen on how The North Laine, an example of an urban village or cultural quarter, came into being as a vernacular, countercultural and cool local space, and how contemporary forces and process of globalization are engaging with that space today. In understanding the genesis of the space, some familiar patterns that are common with the wider literature were evident here. The North Laine shares the close-knit street layout, the distinctive culture, a sense of history and distinguishing buildings that appear in other urban villages. It also emerges from a period of postindustrial decline and residential disuse following that period of decline. There are, however, several important and crucial differences. The area in which The North Laine stands contained elements that from the historical beginning of the building of Brighton in early modernity affords difference. The main element being that Brighton as a whole was construed to be somewhere that was outside the usual norms 
and boundaries (both geographical and moral) of other English towns and cities. This key element then laid down in the symbolic and cultural order of the area providing the cultural resources of experimentation and permissive license. Other elements that separate The North Laines from other cultural quarters include the particular way that Brighton underwent the transition from feudalism and into capitalistmodernity.

5.2 All urban space is dynamic and in a constant process of becoming and the North Laine is no different. The main motor for change and movement in this space is one common to all urban spaces: globalization. What this study revealed was that the effects of globalization are far from being wholly negative. The street art, as the prime example, displays how global cultural influences can meld with local symbols and contexts that further heighten and nuance a sense of the local. The particular array of styles, the form of the buildings that the murals are painted on, the way in which they are encountered walking through particular streets could only happen in The North Laine. There is a further nuance, however, parallel to the glocalization of the street art there also exists the standardizing and homogenizing presence of large-scale corporate concerns.

5.3 The North Laine shares many of the classic elements of an urban village or cultural quarter: it possesses, for instance, the idiosyncratic buildings, the tight street pattern, the cultural use of space emerging out of a period of deindustrialisation. It does, however display distinct characteristics that afford the area with further distinction. The designation of Brighton as a place of escape and emotional excitement adds a historical sense of permission and license to be different that still arguably pervades The North Laine today. The people attracted to The North Laine in its decline also differed from the artists that are commonly attracted to similar areas offering cheap housing and an interesting place to live. Their motivations were political and this alternative political tradition adds a different dimension to the area.

5.4 From inspecting the history, The North Laine qualifies as a vernacular space that has developed organically over time. This does not mean that everything about it is essentially local. The influence of globalization is present, but not necessarily negative. A distinct fusion of the local and the global is present, notably in the street art, which adds to the sense of the unique local, though the effect of the increasing presence of multi-national chain stores in the area may exert changes that could potentially destabilize and reorder the area.

5.5 Overall, this essay on The North Laine provides further insights into the formation of cultural quarters or urban villages by highlighting the interrelationship of local historical forces and global processes. The street art in particular providing a useful example of how the local and the global form a moment of glocalization. Whether or not The North Laine continues as a distinctive area is yet to be seen, but as with other examples of urban villages and vernacular cultural quarters it indicates one way that urban space could be: small-scale and emerging out of the activities, beliefs and traditions of the people who live there as opposed to the planned, impersonal disenchanted corporate spaces that are also evident in many urban spaces.

\section{References}

BELL, D. and Jayne, M. ed. 2004 City of Quarters: Urban Villages in the Contemporary City. Aldershot: Ashgate.

BENJAMIN, W. (1999) Illuminations. London: Pimlico.

BENNETT, P. (2011) 'We once ran the Solstice Bookshop, 1977-1982', North Laine Community Association. $<$ http://www.nlcaonline.org.uk/page_id_863_path_0p18p95p.aspx>. [accessed 19/12/11]

BOVONE, L. (2004) 'Fashionable Quarters in the Postindustrial City: The Ticinese of Milan', City and Community, 4(4): 359-380.

BROWN, A., O'Connor, J., \& Cohen, S. (2000) 'Local music policies within a global music industry: cultural quarters in Manchester and Sheffield', Geoforum, 31(4): 437-451.

CARDER, T. (1990) The Encyclopaedia of Brighton. Brighton: East Sussex County Council. CHAPLIN, E. (1994)

Sociology and Visual Representation. Oxfordshire: Routledge.

COHEN, S. (1972) Folk Devils and Moral Panics. London: MacGibbon and Kee CRARY,

J. (1999) Suspensions of Perception. Cambridge, MA: MIT Press.

CROW, G. (2002) Community studies: fifty years of theorization. Sociological Research Online, 7/3

$<$ http://www.socresonline.org.uk/7/3/crow.html>.

DECERTEAU, M. (2002) The Practice of Everyday Life. 2nd ed. Berkley, CA: University of California Press. FROMM, E.

(1966) Marx's Concept of Man. New York: Ungar.

FULLER, J. (2011) 'Bill and 'The Unicorn", North Laine Community Association.

$<$ http://www.nlcaonline.org.uk/page_id_867_path_0p18p95p.aspx > [accessed 20/12/11]

GANS, H. (1962) The Urban Villagers: Group and Class in the life of Italian-Americans. New York: Free Press. GORZ, A. (1999)

Reclaiming Work: Beyond the Wage-based Society. Cambridge: Polity Press.

HAMILTON, C. (2003) Growth Fetish. London: Pluto Press.

HARVEY, D. (1989) The Condition of Postmodernity. Oxford: Basil Blackwell. 
HENNY, L. (1986) 'Theory and practice of visual sociology', Current Sociology, 34(3): 1-76. JACOBS, J. (1961)

The Death and Life of Great American Cities. Harmondsworth: Penguin. KLEIN, N. (2000) No Logo: No Space,

No Choice, No Jobs. London: Flamingo.

LEFEBVRE, H. (1991) The Production of Space. Oxford: Blackwell. MASSEY, D.

(1994) Space, Place and Gender. Cambridge: Polity Press.

MAY, T., Perry, B., Le Gales, P., Sassen, S., \& Savage, M. (2005) 'The future of urban sociology', Sociology, 39: 343-370.

MCGUIGAN, J (2011) 'From cultural populism to cool capitalism', Art and the Public Sphere, 1 (1) pp. 7-18. MERRIFIELD, A. (2002)

Metromarxism: A Marxist Tale of the City. London: Routledge.

MILlER, D., Jackson, P., Thrift, N., Holbrook, B., \& Rowlands, M. (1998) Shopping, Place and Identity.

London: Routledge.

MONTGOMERY, J. (1995) The Story of Temple Bar: Creating Dublin's Cultural Quarter', ? Planning Practice and Research, 10 (2): $135-172$.

MONTGOMERY, J. (1998) 'Making a City: Urbanity, Vitality and Urban Design', ? Journal of Urban Design, 3 (1): 93-116.

MONTGOMERY, J. (2003) 'Cultural Quarters as Mechanisms for Urban Regeneration: Conceptualising Cultural Quarters',? Planning

Practice and Research, 18(4): 293-306.

MONTGOMERY, J. (2005) 'Dublin, Sheffield, Manchester and Adelaide: cultural quarters as mechanisms for urban regeneration' in E. Charlesworth (ed), City Edge: Case Studies in Contemporary Urbanism. Oxford: Architectural Press. pp84-101.

PARK, R.E. (1950) Race and Culture. Illinois: Free Press.

PORTER, E., and Barber, A. (2007) Planning the cultural quarter in Birmingham's Eastside. European Planning Studies, 15 (10). pp. 1327-1348.

RITZER, (2008) The MacDonaldization of Society. 5th ed. California: Pine Forge Press.

ROBERTSON, R. (1995) Glocalization: 'Time-space and homogeneity-heterogeneity', in M. Featherstone, S. Lash \& R. Robertson (eds) Global Modernities. London: Sage. pp25-44.

SASSEN, S. (2000) Cities in a World Economy, $2^{\text {nd }}$ edn. Thosdand Oaks, CA: Sage. SASSEN, S. (2001)

The Global City: New York, LondonTokyo, . London Routledge.

SAVAGE, M., Warde, A., \& Ward, K. (2003) Urban Sociology, Capitalism and Modernity, $2^{\text {nd }}$ edn. Houndsmills: Palgrave MacMillan.

SHIELDS, R. (1991) Places on the Margin: Alternative Geographies of Modernity. London: Routledge. SHIELDS, R. (2004)

'Visualicity', Visual Culture in Britain, 5(1): 23-35.

SHORTHOSE, J. (2004) 'Nottingham's de facto Cultural Quarter: The Lace Market,

SHORTHOSE, J. (2004) 'The engineered and the vernacular in cultural quarter development,' Culture and Capital, 28(3): 159-178.

SIMMEL, G. (1971) 'The Metropolis and Mental Life', in D. Levine (ed.) Georg Simmel: On Individuality and Social Forms. Chicago: University of Chicago.

STRANGLEMAN, T. (2004) ' Ways of (not) seeing work: The visual as a blind spot in WES?', Work, Employment and Society, 18(1): 179-192.

THOMPSON, C.J. \& Arsel, Z. (2004) 'The Starbucks brandscape and consumers' (anticorporate) experiences of glocalization' Journal of Consumer Research, 31: 631-643.

TIESDALL, S. (1995) 'Tensions between revitalization and conservation: Nottingham's Lace Market', Cities, 12(4): 231-241.

WOGAN, P. (2004) 'Deep hanging out: reflections on fieldwork and multisited Andean ethnography', Identities: Global Studies in YOUNG, M. \& WILLMOTT, P. (1962) Family and Kinship in East London. Harmondsworth: Penguin.

WOOD, E.M. (2002) The Origin of Capitalism: A Longer View. London: Verso.

ZUKIN, S. (1989) Loft Living: Culture and Capital in Urban Change. New Brunswick, NJ: Rutgers University Press.

ZUKIN, S. (1998) 'Urban Lifestyles: Diversity and Standardisation in Spaces of Consumption', Urban Studies,

35(5-6): 825-839. 